\title{
A RARE CASE PRESENTATION OF SIMPLE BONE CYST IN CLAVICLE
}

\author{
M. P. R. Vittal ${ }^{1}$, B. Pardhasaradhy², Shyam Kumar 3 , Y. Nageswar Rao ${ }^{4}$, M. Qamar Azeez ${ }^{5}$
}

\section{HOW TO CITE THIS ARTICLE:}

M. P. R. Vittal, B. Pardhasaradhy, Shyam Kumar, Y. Nageswar Rao, M. Qamar Azeez. "A Rare Case Presentation of Simple Bone CYST in Clavicle". Journal of Evolution of Medical and Dental Sciences 2015; Vol. 4, Issue 41, May 21; Page: 7207-7212, DOI: 10.14260/jemds/2015/1044

\begin{abstract}
Simple bone cyst represent approximately 3\% of all primary bone tumors sampled for biopsy and nearly always occur during the first two decades of life. They are common in metaphyseal region of long bones. Clavicle is rare site for this lesion and not many have been reported in literature. We report a case of Histopathologically confirmed Simple bone cyst in a 65 yrs old manual laborer who presented with pain and swelling of long duration. The occurrence of this lesion at unusual age and at unusual location carries a lot of diagnostic dilemma and various differentials like $\mathrm{ABC}$, Eosinophilic granuloma, and enchondroma were considered only to confirm simple bone cyst on HPE. The symptoms were relieved after resection of lesion. Clavicle was reconstructed with tricortical iliac crest bone graft. At 18th month follow up the patient had no recurrences and had a good functional outcome.
\end{abstract}

KEYWORDS: Bone Cysts [C04.182.089], Clavicle [A02.835.232.087.227], Transplantation, Autologous [E04.936.664].

INTRODUCTION: Primary bone tumors of flat bone like clavicle are rare. True benign tumors are much uncommon than metastatic or malignant lesions. Simple bone cyst represents approximately $3 \%$ of all primary bone tumors sampled for biopsy and nearly always occur during the first two decades of life. They are common in metaphyseal region of long bones. Simple bone cysts are very rare in flat bones.

Clavicle is rare site for this lesion and not many have been reported in literature. Smith, ${ }^{1}$ in 1965, Dahlins, ${ }^{2}$ monograph and radiological atlases could find only few cases over a period of 50 years, hence this case is reported.

CASE REPORT: A 65 male presented with insidious onset of swelling and pain in right clavicle from 6 months to our OPD on October 2013. The symptoms were progressive and his past medical and surgical history was unremarkable.

On examination the mass was bony hard in consistency and tender. No other swellings were palpable. Radiography showed cystic lesion at lateral thirds of clavicle with cortical breach and no periosteal reaction, $\mathrm{AC}$ joint was spared, suggestive of differentials as $\mathrm{ABC}$, Eosinophilic granuloma, simple bone cyst and enchondroma. ${ }^{3}$

Basic hematological workup including alkaline phosphatase, serum calcium and ESR was normal. Fine needle aspiration cytology was inconclusive but MRI scan was suggestive of simple bone cyst.

METHODS: Various options available were Curettage, saucerisation, resection, radiotherapy, cryotherapy. 4

Therapeutic option considered was resection of lesion and reconstruction of clavicle with tricortical autologous iliac crest bone graft. Intraoperatively, initially $10 \mathrm{cc}$ syringe was used to 


\section{CASE REPORT}

aspirate the contents and lesion was approached after incising periosteum longitudinally. Inner wall was curetted and electro cautery was done to seal the bleeding wall of the cavity. Open marginal resection was done and the lesion was curetted with ethyl alcohol augmentation and the defect was filled with corticocancellous strip of autologous iliac crest bone graft using a recon plate. Limb was immobilized in cuff and collar. Preoperative diagnosis was confirmed with histopathological examination of curetted specimen.

RESULTS: Post-operative period was uneventful and patient was serially followed up and implant was removed after 12 months and on the latest visit of 24 months cyst was radio logically and clinically completely healed and patient resumed pain free use of upper extremity.

There are quite contradictory reports regarding results. Resection of lesion offers low recurrence rate but cannot be exercised everywhere. Combination of cryosurgery and curettage by few authors shows $82 \%$ control.Radiotherapy can cause radiation induced sarcomas and injury to physis, so it is being used in cases that cannot be operated.

CONCLUSIONS: Recurrence rate may be as high as $100 \%$ but our patient responded well to the treatment and we feel that this case enriches existing data regarding treatment option of simple bone cyst in an unusual elderly patient and in unusual location.

\section{BIBLIOGRAPHY:}

1. Smith j, primary tumors of clavicle.br j radiol.1977; 50: 706-9.

2. Dahlin, d.c. bone tumors.second edition.charles c thomas, publishers, springfield, 1967.

3. ANDERSON, H. S. Lesions of clavicle. Radiology, 1931, 181-186.

4. Jaffe, H.L. tumors and tumor conditions of the bones and joints. Lea \& febiger, philadelphia, 1958.

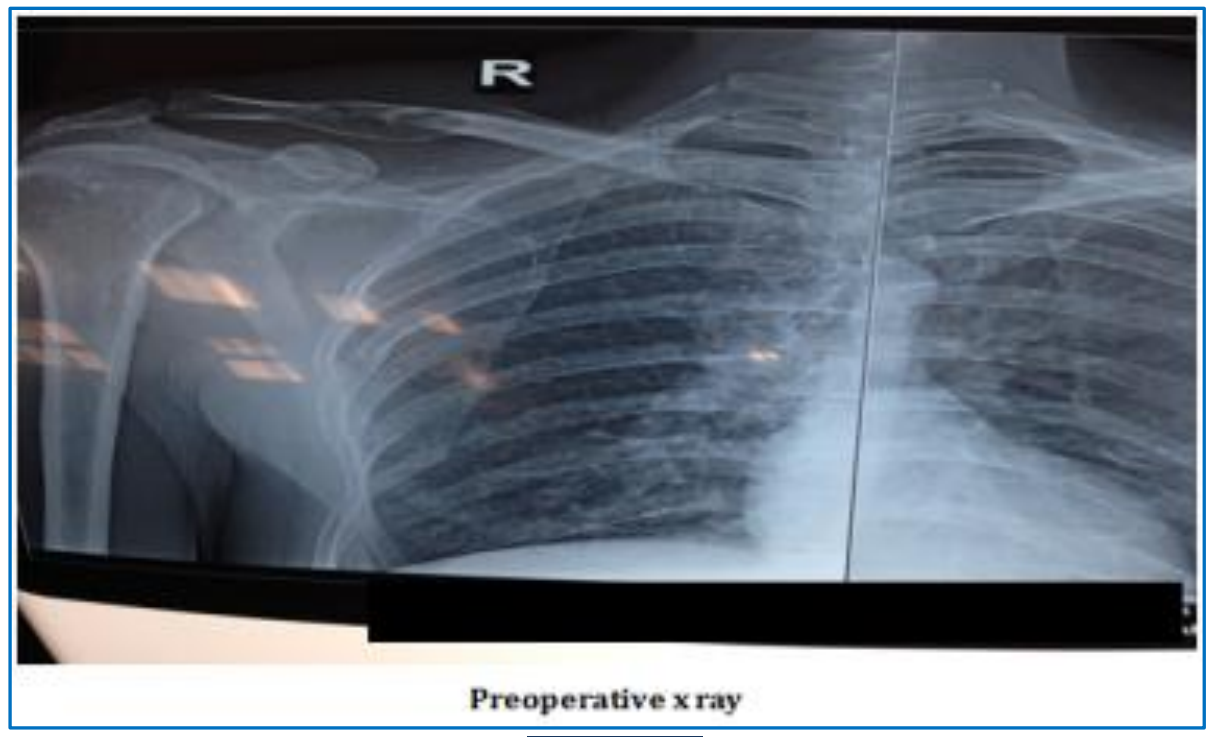

Fig. 1 


\section{CASE REPORT}
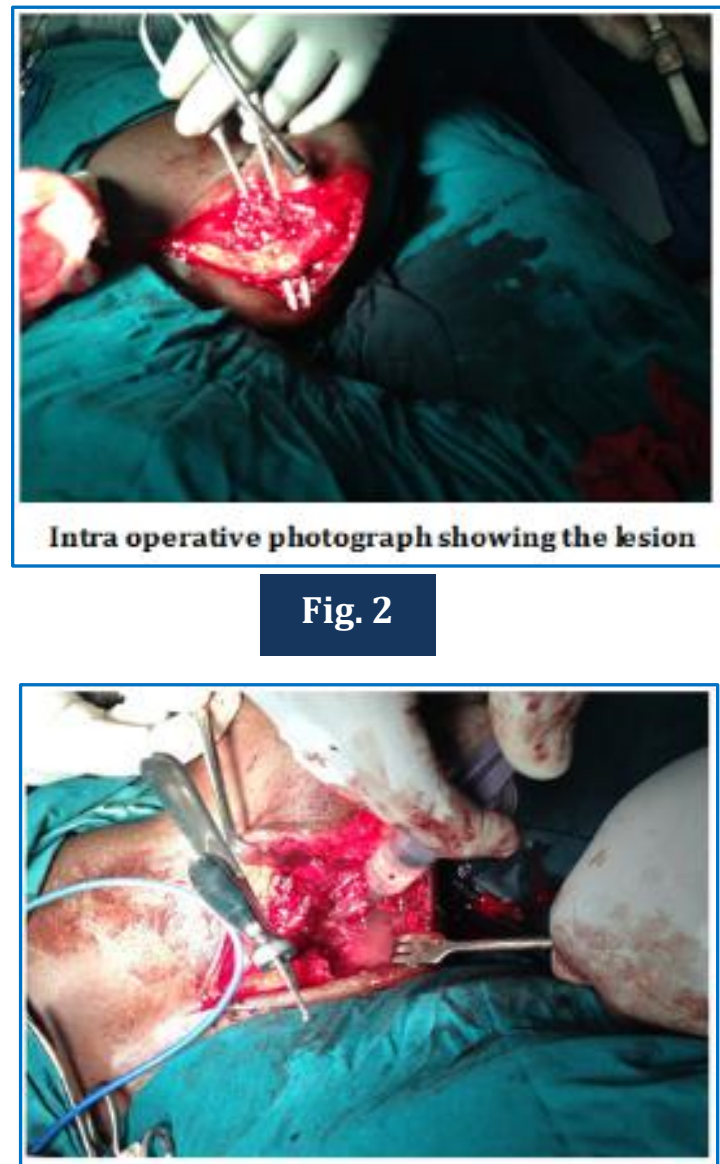

Intraoperative photograph showing ethyl Alcohol augmentation

\section{Fig. 3}

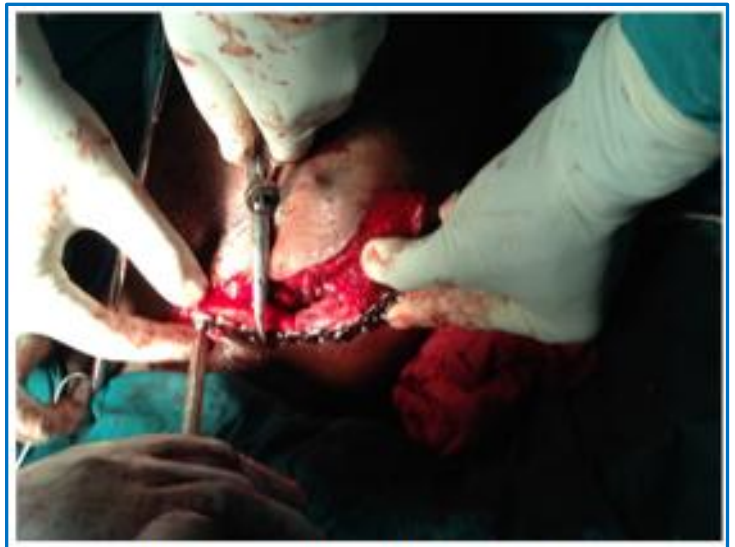

Reconstruction with iliac crest Bone graft and recon plate

\section{Fig. 4}




\section{CASE REPORT}

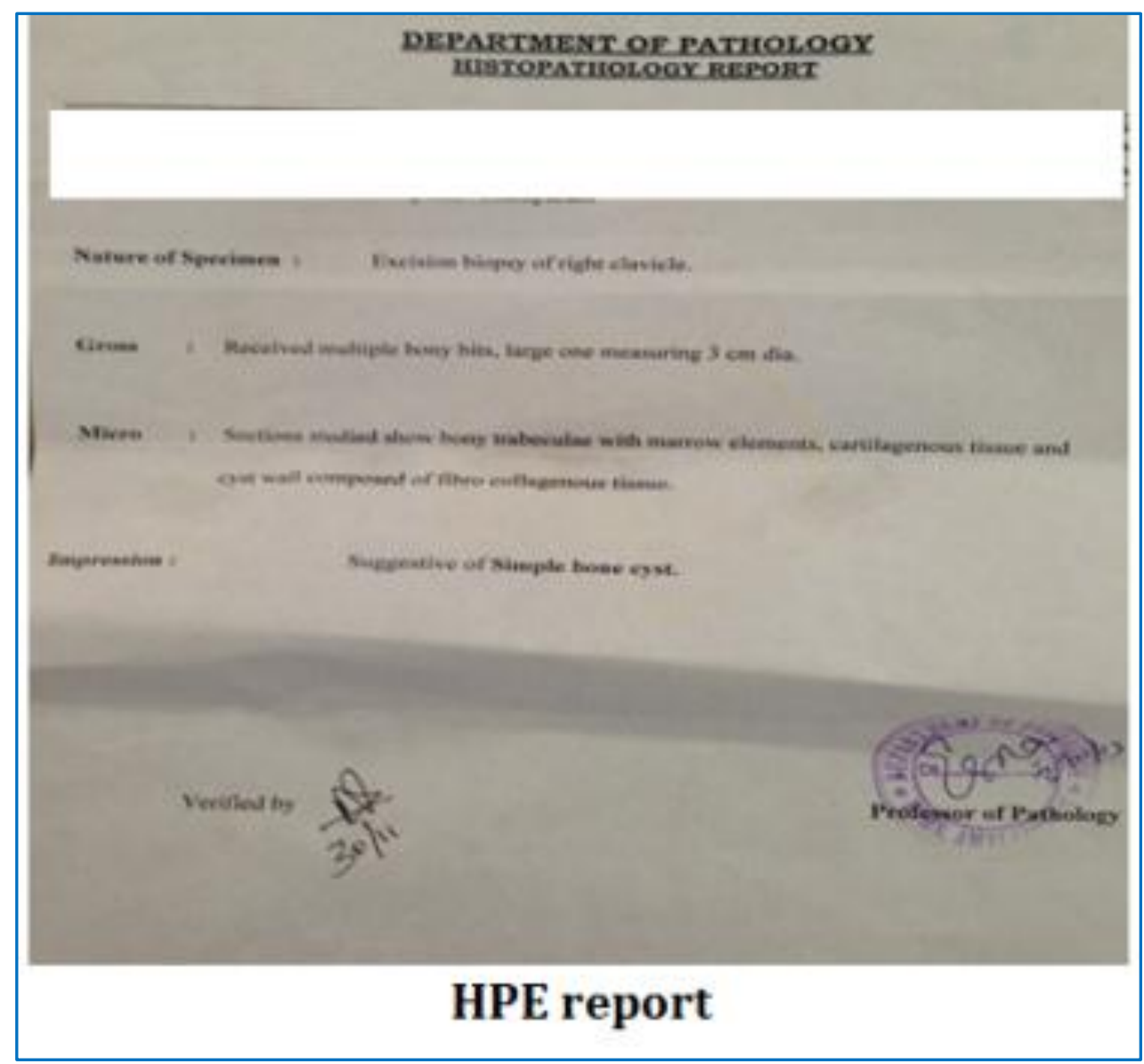

Fig. 5

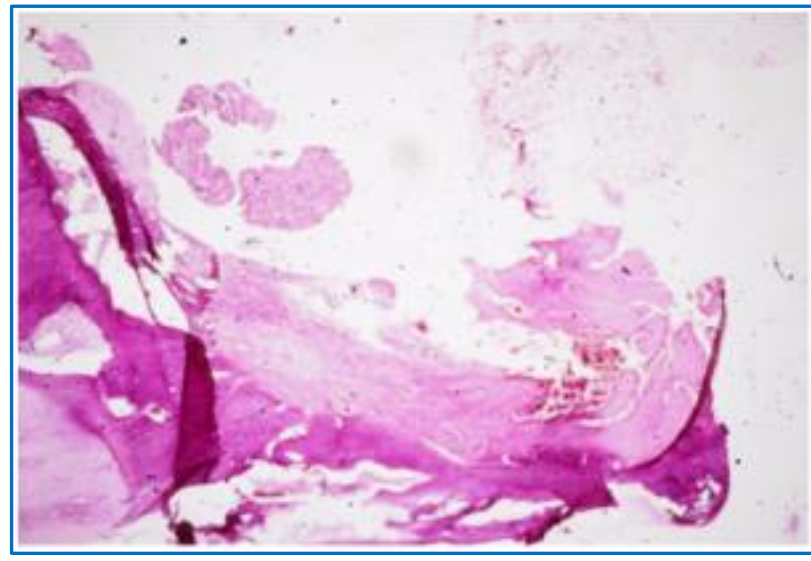

Fig. 6

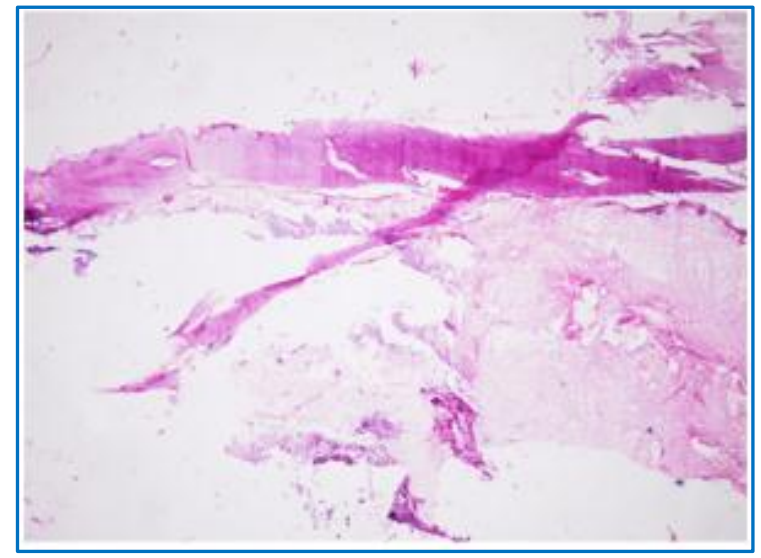

Fig. 7 


\section{CASE REPORT}

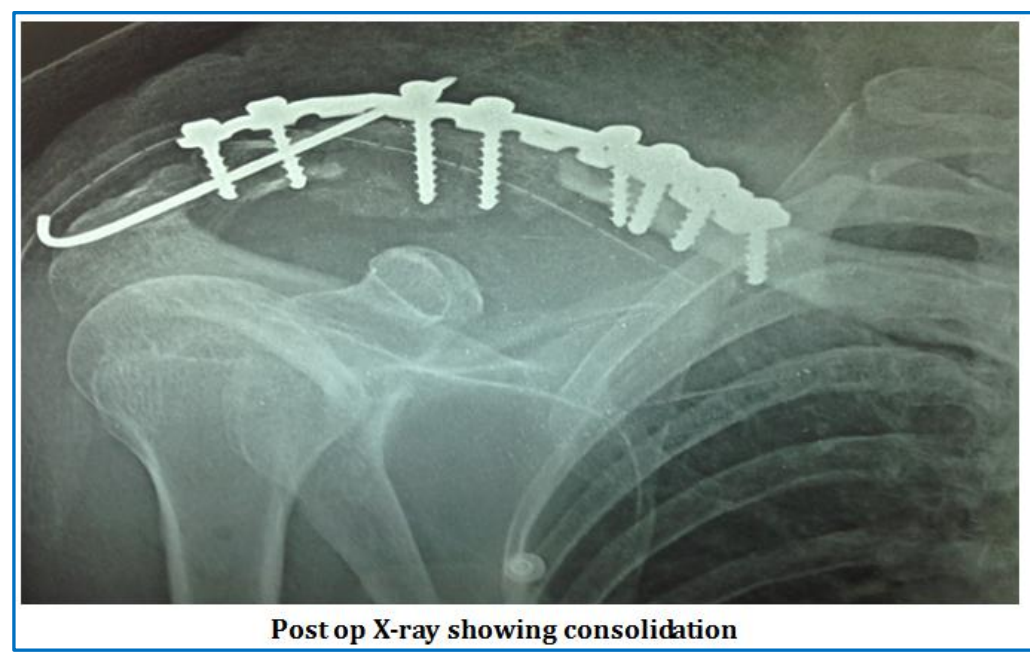

Fig. 8

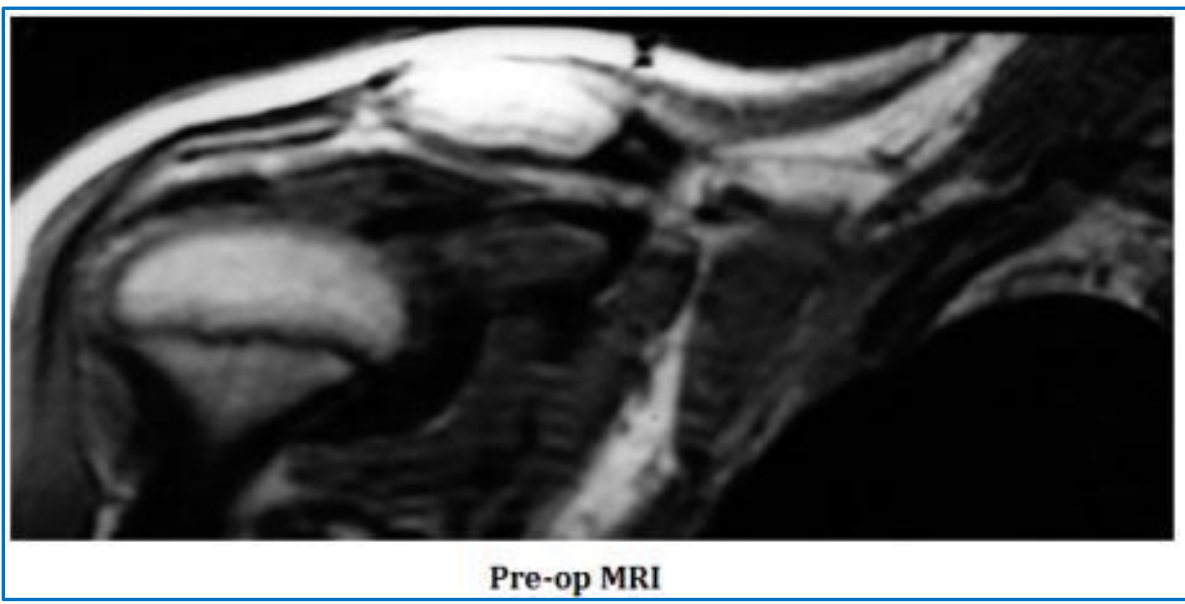

Fig. 9

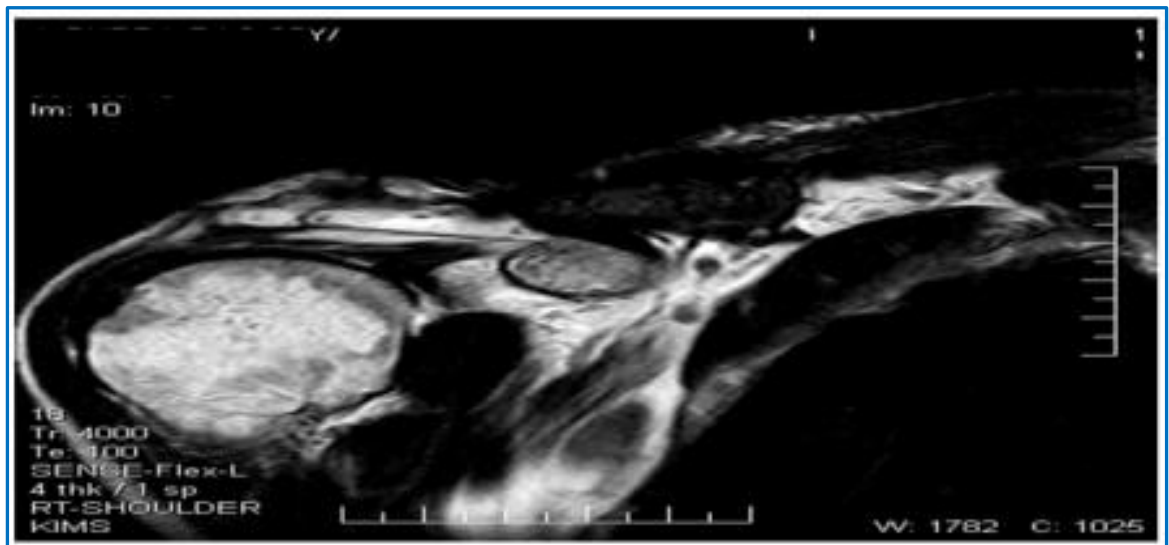

Post-op MRI at 28 months showing no recurrence

Fig. 10 


\section{AUTHORS:}

1. M.P. R. Vittal

2. B. Pardhasaradhy

3. Shyam Kumar

4. Y. Nageswar Rao

5. M. Qamar Azeez

\section{PARTICULARS OF CONTRIBUTORS:}

1. Associate Professor, Department of Orthopaedics, Rangaraya Medical College.

2. Assistant Professor, Department of Orthopaedics, Rangaraya Medical College.

3. Associate Professor, Department of Orthopaedics, Rangaraya Medical College.

FINANCIAL OR OTHER COMPETING INTERESTS: None
4. Professor \& HOD, Department of Orthopaedics, Rangaraya Medical College.

5. Senior Resident, Department of Orthopaedics, Rangaraya Medical College.

\section{NAME ADDRESS EMAIL ID OF THE CORRESPONDING AUTHOR:}

Dr. M. P. R. Vittal,

Department of Orthopaedics, \& Traumatology, Government General Hospital, Kakinada-533001.

Email: azeez.qamar@gmail.com

Date of Submission: 28/04/2015.

Date of Peer Review: 29/04/2015.

Date of Acceptance: 13/05/2015.

Date of Publishing: 21/05/2015. 